\title{
Climate change: impact, adaptation and vulnerability in the water supply of Kathmandu Valley
}

\author{
P. Kumar Jha \\ University of the Sunshine Coast, Australia
}

\begin{abstract}
This study has identified the vulnerability of the water supply system in Kathmandu Valley, Nepal from the impact of the worst case of climate change and has also suggested adaptation strategies to deal with the situation. For this the observed precipitation data, SimCLIM software and the existing literature were used. This study found that existing strategies are insufficient and more than five million people would be deprived of the minimum needed water by 2050 under the driest scenario of climate change. Similarly, the reduction in low flow under the driest scenario or frequent extreme rainfall events under the wettest scenario could further degrade the water quality and increase the vulnerability of water supply infrastructures. A combination of strategies can help manage the situation until 2050. The situation, however, would become worse after 2050 due to the projected sharp reduction in precipitation, which would in turn, make all precipitation-dependent water supply strategies ineffective. The result of this study should be used as an indication only as there is no agreement among General Circulation Models (GCMs) in projecting future precipitation. The result of this study is useful for agencies and individuals involved in water supply related planning and policy making

Keywords: water scarcity, climate change, Kathmandu Valley, worst case scenario, SimCLIM.
\end{abstract}

\section{Introduction}

Access to clean water is one of the most important human needs. Climate change combined with the other socio-economic factors such as high rates of population growth and urbanization can reduce the availability of fresh water in the urban 
areas of developing countries [1, 2]. Although well managed systems are less vulnerable, the unexpected trends and uncertainties posed by climate change will increase the vulnerability to the poor and less developed parts of the world [2]. Nepal is one of the Least Developed Countries (LDC), as defined by the United Nations in terms of its low level of national income, less developed human capacity and a high degree of economic vulnerability [3].

Climate change has already been observed in Nepal. Nepal has observed a continuous increase in the average annual temperature of $0.04-0.06^{\circ} \mathrm{C}$ since 1977 $[4,5]$. Unlike temperature, the observed precipitation has not followed any systematic trend and a large periodic, seasonal and spatial variation has existed as per the record since $1948[5,6]$.

Climate change can affect water supply in Nepal by its impact on precipitation, glacier melting and increase in temperature. Snow and glaciers have an important role to play in the water availability of Nepal as they contribute to the dry season river flow $[2,7,8]$. All of the glaciers in Nepal have been found to be retreating at a higher rate than other parts of the world $[9,10]$. The river flow in the glacier-fed rivers is projected to increase until the year 2030 or 2040 followed by a gradual decrease $[11,12]$. On the other hand, an increase in temperature can also raise the water demand. A study in the UK has found that a $1.1^{\circ} \mathrm{C}$ rise in temperature can increase average per capita water demand by $5 \%[13]$.

A wide range of uncertainties exist in projecting the future climate in Nepal due to the limitations of GCMs to capture complex topographical induced climatic variations $[6,14-18]$. Although there is an agreement among GCMs in projecting temperature increase, no such agreement exists in projecting precipitation [8-14].

Kathmandu Valley is situated in the middle mountain region of Nepal [19]. It is the largest economic and population centre of Nepal, as it contributes $30 \%$ of the country's gross domestic product (GDP) and is home to $50 \%$ of the total urban population [20]. The rapid population growth and unplanned urbanization have threatened the future socio-economic contribution. This is due in part to the impact of such unplanned growth on sufficiency of the water supply system.

The Kathmandu Upatyka Khanepani Limited (KUKL) is the only agency responsible for the management of piped water supply distribution in Kathmandu Valley. The main source of water for the KUKL is the Bagmati River at Sundarijal. The Valley's current water demand is about 280 million litres per day (MLD) but the KUKL is only able to supply 86 MLD during the dry season and 105 MLD during the wet season [21]. Other sources of water to meet the remaining demand are: ground water including the stone spouts and wells; private tankers which carry water from springs and rivers located far from Kathmandu Valley and bottled water [20].

The Government of Nepal (GON) has taken several efforts to meet the growing water requirement for Kathmandu Valley. The GON initiated an inter basin water transfer project called the Melamchi Water Supply Project (MWSP) in 2001 to supply an additional $170 \operatorname{MLD}\left(1.97 \mathrm{~m}^{3} / \mathrm{s}\right)$ of water from the Melamchi River. However, the adequacy of the dry season river flow has been 
debated even under the present climate, which could become worse under the changed climatic conditions [22]. The GON has also formulated, reformed and implemented several policies related to water supply to increase access of people to adequate and safe drinking water [20, 22-27].

This study has assessed the impact of climate variability and change in the vulnerability of the water supply of Kathmandu Valley, the capital city of Nepal and has suggested possible adaptation strategies considering the worst case scenario of climate change.

\section{Study area and methodology}

This study focused on different parts of Kathmandu Valley covered by the KUKL service areas [20].

Kathmandu Valley is well represented by meteorological stations of the Department of Hydrology and Meteorology [28]. Among the total 19 weather stations in Kathmandu Valley, four stations (Kathmandu airport, Thankot, Chapagaun and Changu) were selected on the basis of the following criteria:

* stations having daily precipitation time-series data;

* covering the 30 year time period 1980-2009;

* having little missing data and no long consecutive gap periods; and

* representing the major cities and are evenly spaced.

Daily precipitation data of the four stations of Kathmandu Valley from 1980 to 2009 were obtained from the DHM. These data were entered in SimCLIM to analyse the observed trend and perturb the future trends under the worst case scenario and an average case scenario of climate change. The worst case scenario was projected by using the GCM which shows the driest scenario, SRES A1FI emissions scenario and a high level of climate sensitivity. On the other hand, the average case scenario used an ensemble from 21 GCMs available in SimCLIM, SRES A1B emissions scenario and a mid level of climate sensitivity.

The rainwater tank model of SimCLIM was used to identify the potential of rainwater harvesting under existing and changed climatic conditions. The capacity of rainwater tanks to supply water regularly was assessed for various sizes of tanks with different sizes of roof catchments based on the assumptions that households cannot tolerate more than seven days without water in the tank and dry periods of more than seven times-in-100 years. It was also assumed that the tank was initially full [29].

The spatial scenario generator of SimCLIM was used to project spatial change in temperature and precipitation for Kathmandu Valley and the Melamchi River catchments area. The Melamchi River catchment area was taken up to the point from where water diversion has been proposed. Similarly, the extreme event analyser of SimCLIM was used to project the change in frequencies of extreme rainfall events using the GCM which shows the wettest scenario. Impact of climate change, including extreme rainfall, events on water quantity and quality was assessed based on the existing literature. 
Water demand was projected based on the projection of the Asian Development Bank's for the Kathmandu Valley [20]. Water scarcity was analysed based on the potential of water supply sources to supply water under changed climatic conditions and projected water demand for future.

Adaptation strategies were developed based on their potential to meet clean and adequate water need under changed climatic conditions.

\section{Results}

The average annual precipitation of Kathmandu Valley was from $1365 \mathrm{~mm}$ to $1872 \mathrm{~mm}$ between 1980 and 2009; however most (76-82\%) of the rain fell during the four months of monsoon season (June-September), causing water scarcity during the other months. The average annual precipitation has not followed any systematic trend, with periodic and inter-annual fluctuations (Figure 1).

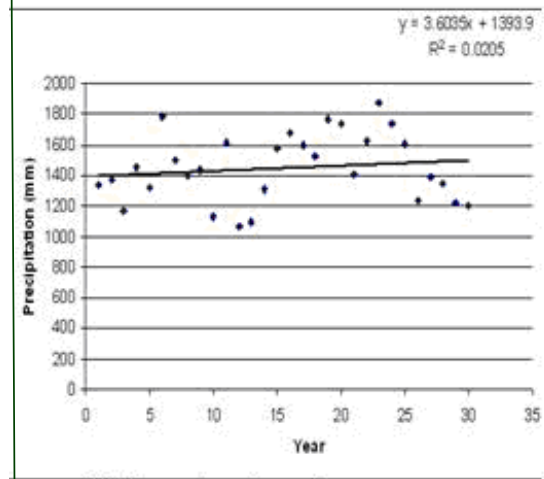

Kathmandu airport

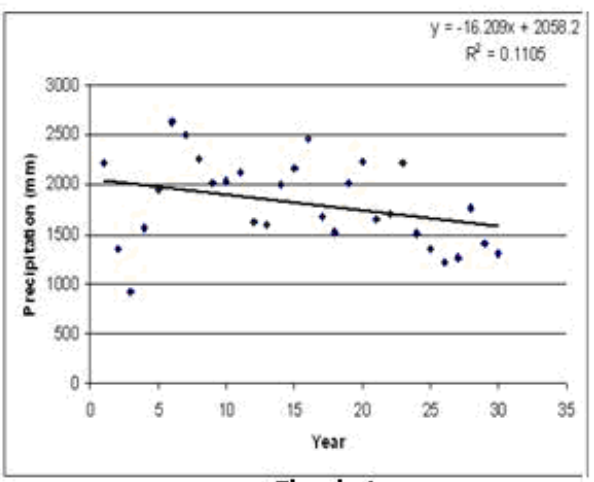

Thankot

Figure 1: Observed annual precipitation trend for different stations of Kathmandu valley between 1980 and 2009.

Among the 21 GCMs used for this study, six GCMs project a decrease in precipitation, while the others project an increase in precipitation. The expected changes in precipitation would be in the range of $-20 \%$ to $+37 \%$ per degree Celsius of warming.

The GCM IPSL-CM40, which shows the driest scenario, was adopted for the purpose of this study. The frequency of extreme rainfall events, however, was projected using GCM MRI-232A, which shows the wettest scenario.

The average annual precipitation for Kathmandu Valley is projected to be in the range of $634 \mathrm{~mm}$ to $812 \mathrm{~mm}$ by 2050 and $70 \mathrm{~mm}$ to $120 \mathrm{~mm}$ by 2100 based on the perturbation of the observed data for the worst case scenario of climate change. The spatial scenario generator of SimCLIM shows that the decrease in precipitation is expected to be in all areas of Kathmandu Valley with a high rate of decrease in the major city areas. The months receiving high amounts of precipitation are expected to be limited to three by 2050 and two by 2100 (Figure 2). Similarly, rainy days are expected to decline up to $29 \%$ by 2050 and 
would be in the range of seven to ten days per year by 2100 (Table 1). The temperature is projected to increase in the range of $1.8^{\circ} \mathrm{C}-1.9^{\circ} \mathrm{C}$ by $2030,3.7^{\circ} \mathrm{C}$ $3.8^{\circ} \mathrm{C}$ by 2050 and $9.3^{\circ} \mathrm{C}-9.7^{\circ} \mathrm{C}$ by 2100 for all areas under the worst case scenario. In contrast, a slight increase in the average annual precipitation is expected under the average case scenario of climate change generated from an ensemble of the 21 GCMs.
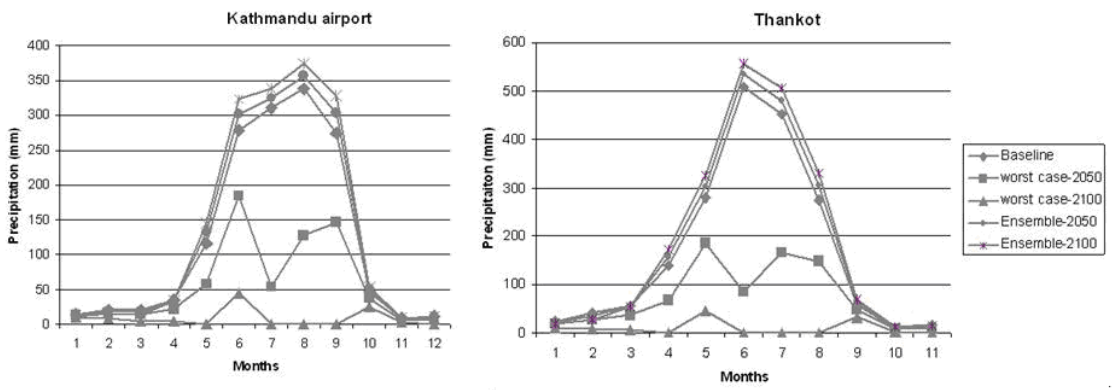

Figure 2: Monthly precipitation data for the worst case and an average scenario of climate change compared to the baseline for different stations of the Kathmandu valley.

The expected decrease in precipitation for the Melamchi River catchment during the dry season (January-April) is up to $34 \%$ by 2050 and $80 \%$ by 2100 under the worst case scenario of climate change. The projected rise in mean annual temperature is in the range of $4^{\circ} \mathrm{C}-5^{\circ} \mathrm{C}$ by 2050 and $9.9^{\circ} \mathrm{C}-10.9^{\circ} \mathrm{C}$ by 2100 compared to 1990 . Both scenarios show a decrease in precipitation during the dry season for the Malamchi River catchment.

Table 1: $\quad$ Projected change in total number of rainy days under the changed climatic condition for different scenarios of climate change.

\begin{tabular}{|c|c|c|c|c|c|c|c|c|c|}
\hline \multirow[b]{2}{*}{ Stations } & \multicolumn{5}{|c|}{ Worst case scenario } & \multicolumn{4}{|c|}{ Average case scentario } \\
\hline & Baselinie & 2015 & 2030 & 2050 & 2100 & 2015 & 2030 & 2050 & 2100 \\
\hline $\begin{array}{l}\text { Kathmentidu } \\
\text { artionott. }\end{array}$ & 187 & 182 & 178 & 143 & 10 & 188 & 100 & 1010 & 180 \\
\hline Tharkot & 187 & 185 & 180 & 161 & 11 & 187 & 190 & 189 & 187 \\
\hline Chaptagaluti & 177 & 171 & 162 & 125 & 9 & 177 & 177 & 177 & 177 \\
\hline Changl & 180 & 184 & 178 & 150 & 7 & 188 & 189 & 189 & 187 \\
\hline
\end{tabular}

From the rainwater tanks model of SimCLIM it was found that the capacity of rainwater tanks to supply water on a regular basis increases considerably from tank sizes of 50000 litres upward when fed from a roof area of $75 \mathrm{~m}^{2}$ under the existing climatic condition (Figure 3). The modelling showed that the impact of climate change is greater for tank sizes of 50000 litres upwards; and that the impacts are minimal or none for tanks of 20000 litres or less (Figure 4). The 
model also found that climate change would impact all locations in Kathmandu Valley. From the model it was found that it would be possible to collect an extra 133 litres per day (LPD) of water by enlarging tanks sizes from 50000 litres to 100000 litres and roof areas from $75 \mathrm{~m}^{2}$ to $150 \mathrm{~m}^{2}$ in 2050 under the worst case scenario of climate change. However, this strategy would be less effective by 2100 as evident from the finding that the increase in water supply per day is just 46 LPD despite an increase in tank size from 20000 litres to 150000 litres and roof area from $75 \mathrm{~m}^{2}$ to $200 \mathrm{~m}^{2}$.

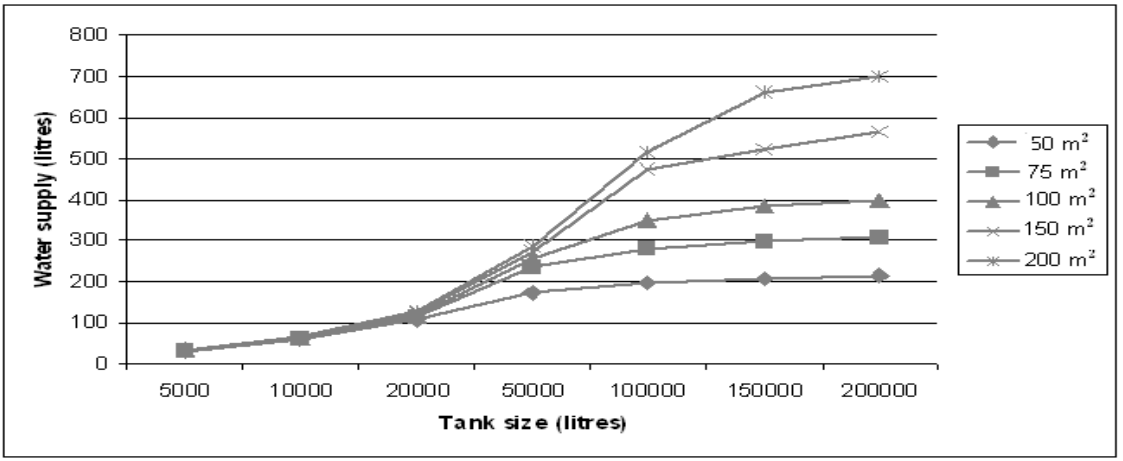

Figure 3: Amount of water that can be collected from various sizes of roofs and tanks under the current climate for the Kathmandu airport areas.

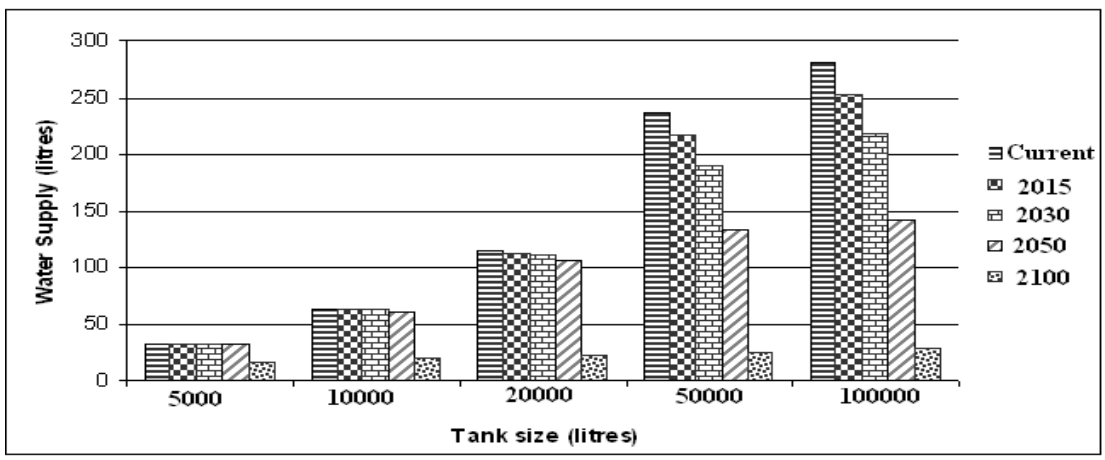

Figure 4: Impact of climate change on potential of different sizes of rainwater tank to harvest rainwater at household level assessed under the worst case scenario.

In terms of cost, the rainwater harvesting at a domestic level is more expensive (US\$ 2.9 per kilo litre) than the water supply from the MWSP in the short term but would be less expensive by the year 2083 due to a provision of a $3 \%$ annual increase in the water tariff of the proposed MWSP [20, 30, 31]. 
The model simulation also showed that extreme rainfall events would occur more frequently under the changed climatic conditions in all areas of Kathmandu Valley. Return periods of extreme rainfall events were found to be reduced for all stations under the wettest scenario of climate change (Table 2). The situation is expected to worsen by 2100 when such extreme events could occur every year.

Table 2: Impact of climate change on return periods of extreme rainfall events.

\begin{tabular}{|c|c|c|c|c|}
\hline \multirow[b]{2}{*}{ Stations } & \multirow[b]{2}{*}{$\begin{array}{l}\text { Extreme rainfill } \\
\text { (mm) }\end{array}$} & \multicolumn{3}{|c|}{ Return period (year) } \\
\hline & & $\begin{array}{l}\text { Current } \\
\text { climate }\end{array}$ & $\begin{array}{l}\text { Wettest } \\
\text { scenatio for } \\
2050\end{array}$ & $\begin{array}{l}\text { Wettest } \\
\text { sontario for } \\
2100\end{array}$ \\
\hline Kathmandu & 177 & 169 & 52 & 1 \\
\hline Tharikot. & 300 & 144 & 76 & 1 \\
\hline Chapagaun & 200 & 53 & 23 & 1 \\
\hline Changu & 165 & 228 & 60 & 1 \\
\hline
\end{tabular}

\section{Discussion}

The findings of this study related to climatic trends and projections are similar to the findings of the $[5,14]$. The magnitude of change, however, is higher as this study considered the highest emissions scenarios and a high degree of climate sensitivity. Sharma and Shakya [32] also found a decrease in the average annual river flow of Bagmati River based on the observed data from 1965-2000. The Melamchi River catchment is situated on the Indrawati River basin which is a part of the Koshi River basin. Most of the studies related to the Melamci River catchment have projected climate using GCMs showing an increase in precipitation and hence have predicted an increase in the river flow [11, 12, 33]. This study has used the driest scenario; therefore, the results are different from that of other studies.

The projected increase in temperature and decrease in precipitation is likely to significantly reduce the potential of existing supply sources such as river flow and groundwater [31,34]. The proposed water transfer from the MWSP is expected to be less affected until 2050 unless the melted water contribution declines by more than $40 \%$. However, the situation is expected to worsen as time progresses and the river flow would be just enough to maintain the minimum environmental flow by the end of the century even if the glacier melted water contribution remained unchanged. The significant reductions in low flow and increase in temperature could also degrade the environmental quality [32]. These factors proved that the inter-basin water transfer project is less suitable to meet the growing water demand considering the worst case scenario of climate change. The capacity of all precipitation-dependent water supply sources is expected to significantly decrease by the end of the century due to a sharp reduction (up to 95\%) in precipitation under the worst case scenario. 
On the other hand, water demand is expected to grow continuously because of the expected increase in population in Kathmandu Valley. The number of people without access to minimum needed water would be 5.21 million people by 2050 and 14.67 million people by 2100 even after the proposed water transfer from the MWSP. This is based on the population projection of ADB for the KUKL service area and a minimum water requirement of 100 litres per capita per day (lpcd), as per the World Health Organization standard [35]. This figure could be still higher when the impact of temperature rise on the increase on water demand is considered.

Considering a significant decrease in potential of precipitation-dependent water sources recycling and reusing water after treatment is the most reliable adaptation strategy. Despite being hygienic scientifically, it is not easy to convince people to use recycled water, probably for at least for some decades. However an easy start could be to recycle grey water and use it for non potable uses such as bathroom, toilet, washing and garden; although full recycling needs to be promoted gradually.

At the same time it is also necessary to take measures to reduce the current trend of rapid population growth. Urban planners agree on the fact that Kathmandu Valley has a carrying capacity of approximately five million people only from the perspective of providing basic services and disaster management [20].

Demand management strategies can also help prevent a sharp increase in per capita water demand. Although the existing pricing structure of the KUKL is in line with the marginal use principle, its effectiveness needs to be tested. Similarly, water use efficiency could be achieved by the introduction of water efficiency labelling, regulatory compliances and motivating people. Under the existing system leakage reduction can save 43 MLD of water, which would be higher under the worst case scenario of climate change.

The design of water supply infrastructures, including the water treatment plants, need to consider the increased vulnerability posed by the change in frequency of extreme rainfall events under the changed climatic conditions [36$38]$.

The vulnerability is further increased by the low level of adaptive capacity of Nepal in general and the poor people of Kathmandu Valley in particular [39, 40]. The role of international and regional cooperation is thus crucial to help develop preparedness.

Reliability of this study, however, depends on factors such as the accuracy of data of the DHM, reliability of GCMs and SimCLIM in projecting the future climate. The reliability of GCMs to project the future climate for Nepal, however, is reduced by several limitations [6, 14-16]. Therefore the results of this study need to be taken as an indication only. It is better to hope for the best but be prepared for the worst.

\section{Conclusion}

The aim of the study was to assess the vulnerability of the water supply system in Kathmandu Valley to the impact of climate change and suggest adaptation 
strategies. This study found that the capacity of the existing and potential water supply sources is expected to reduce significantly by the end of this century under the worst case scenario of climate change. The high rate of population growth combined with the reduction in water supply is expected to increase water scarcity for more than five million people by 2050 with the existing supply even after the completion of the MWSP. Similarly, a significant reduction in low flow or extreme rainfall events under the wettest scenario would degrade the water quality and thus increase health risks for millions of people and increase the vulnerability of water supply infrastructures.

A combination of strategies such as rooftop rainwater harvesting and artificial ground water recharge, reducing leakage, grey water recycling along with the existing supply and completion of the MWSP would be able to meet water demand until 2050. However, the situation is expected to worsen after 2050 due to a significant reduction in the capacity of precipitation-dependent water supply sources from the sharp reduction (up to 95\%) in precipitation when only limited options such as full recycling and population control would be available.

There is a need to carry out further research to remove uncertainties in climate projection and identifying the impact of the driest scenario of climate change on water availability. This study also recommends mainstreaming climate change adaptation considerations in water supply related planning and policy making. Considering the low financial capacity of Nepal and uncertainties in climate change projections it is advised to begin with no/low regret adaptation activities and move forward based on the principles of adaptive management.

\section{References}

[1] O’Hara, J. K. \& Georgakakos, K. P., Quantifying the Urban Water Supply Impacts of Climate Change. Water Resources Management, 22(10), 2008, pp. 1477-1497.

[2] IPCC, 'Climate change 2007: impacts, Adaptation and vulnerability: contribution of working group II to the fourth assessment report of the Intergovernmental Panel on Climate Change. Cambridge University Press, 2007.

[3] UNOHRLLS, "Least Developed Countries", UN Office of the High Representative for the Least Developed Countries, Landlocked Developing Countries and Small Island Developing States, www.unohrlls.org/en/home/.

[4] Shrestha, A. B., Wake, C. P., Mayewski, P. A. \& Dibb, J. E., Maximum temperature trends in the Himalaya and its vicinity: An analysis based on temperature records from Nepal for the period 1971-94. Journal of Climate, 12(9), pp. 2775-2775-2786, 1999.

[5] Marahatta, S., Dongol, B. S. \& Gurung, G. B., Temporal and spatial variablity of climate change over Nepal (1976-2005). Practical Action Nepal Office, 2009.

[6] Shrestha, A. B., Wake, C. P., Dibb, J. E. \& Mayewski, P. A., Precipitation fluctuations in the Nepal Himalaya and its vicinity and relationship with 
some large scale climatological parameters. International Journal of Climatology, 20(3), pp. 317-327, 2000.

[7] Singh, P. \& Singh, V. P., Snow and glacier hydrology. Kluwer Academic Publishers, Dordrecht, 2001.

[8] Agrawala, S., Raksakulthai, V., Aalst, M. V., Larsen, P., Smith, J. \& Reynolds, J., Development and climate change in Nepal: Focus on water resources and hydropower. Organisation for Economic Co-operation and Development (OECD), 2003.

[9] Fujuta, K., Nakazawa, F. \& Rana, B., Glaciological observations on Rikha Samba Glacier in Hidden Valley, Nepal Himalayas, 1998 and 1999. Bulletin of Glaciological Research, 18, pp. 31-35, 2001.

[10] Ageta, Y., N. , Naito, N., Nakawo, M., Fujita, K., Shankar, K., A.P., P. \& D., W., Study project on the recent rapid shrinkage of summeraccumulation typa glaciers in the Himalayas, 1997-1999, 2001.

[11] Immerzeel, W. W., Beek, L. P. H., Konz, M., Shrestha, A. B. \& Bierkens, M. F. P., Hydrological response to climate change in a glacierized catchment in the Himalayas. Climatic Change, 2011.

[12] Gosain, A. K., Shrestha, A. \& Rao, S., Modelling Climate Change Impact on the Hydrology of the Eastern Himalayas: Climate Change Impact and Vulnerability in the Eastern Himalayas ICIMOD, Kathmandu, 2010.

[13] IPCC, Climate Change 2001: Impacts, Adaptation, and Vulnerability. Contribution of WG II to TAR of the Intergovernmental Panel on Climate Change, Cambridge University Press, 2001.

[14] NCVST, Vunerability through the eyes of vulnerable. Institute for Social and Environmental Transition-Nepal (ISET-N, Kathmandu) and Institute for Social and Environmental Transition (ISET, Boulder, Colorado) for Nepal, 2009.

[15] Lin, J.-L., Weickman, K. M., Kiladis, G. N., Mapes, B. E., Schubert, S. D., Suarez, M. J., Bacmeister, J. T. \& Lee, M.-I., Subseasonal Variability Associated with Asian Summer Monsoon Simulated by 14 IPCC AR4 Coupled GCMs. Journal of Climate, 21(18), pp. 4541-4560,4562-4567, 2008.

[16] Kripalani, R. H., Oh, J. H., Kulkarni, A., Sabade, S. S. \& Chaudhari, H. S., South Asian summer monsoon precipitation variability: Coupled climate model simulations and projections under IPCC AR4. Theoretical and Applied Climatology, 90(3-4), pp. 133-159, 2007.

[17] IPCC, Climate change 2007: the physical science basis: contribution of working group I to the Fourth Assessment Report of the Intergovernmental Panel on Climate Change, Cambridge University Press, 2007.

[18] IPCC, Special report on emissions scenarios: summary for policy makers. IPCC, 2000.

[19] LRMP, Land utilization report, Kenting Earth Sciences Limited, His Majesty's Government of Nepal and Government of Canada, 1986.

[20] GHD Pty. Ltd., Kathmandu valley water supply and waste water system improvement: TA 4893-NEP: project feasibility: final report, Asian Development Bank, Kathmandu, 2010. 
[21] Shrestha, R. R., Rainwater harvesting and groundwater recharge for water storage in Kathmandu Valley, Water storage: A strategy for climate change adaptation in the Himalayas, Sustainable Mountain Development, No. 56, winter, ICIMOD, 2009.

[22] Bhattarai, M., Pant, D. \& Molden, D., Socio-economics and hydrological impacts of inter-sectoral and inter basin water transfer decisions: Melamchi Water Transfer projects in Nepal. Proceedings of the Asian Irrigation in transition-responding to the challenges ahead (Asian Institute of Technology, Bangkok, Thailand, 2002.

[23] MPPW, National urban water and sanitation sector policy. Ministry of Physical Planning and Work, Government of Nepal, Kathmandu, 2009.

[24] MPPW, National urban policy, Government of Nepal. Ministry of Physical Planning and Work, Government of Nepal, , Kathmandu, 2007.

[25] MPPW, National drinking water quality standards. Ministry of Physical Planning and Work, Government of Nepal, , Kathmandu, 2006.

[26] NPC, Three year development plan 2010-2012. National Planning Commission, Government of Nepal, Kathmandu, 2010.

[27] MOE, National Adaptation Programme of Action. Ministry of Environment, Government of Nepal, Kathmandu, 2010.

[28] DHM, station network, meteorological stations. Department of Hydrology and Meteorology, Government of Nepal, , Kathmandu, 2011.

[29] Warrick, R. A., Using SimCLIM for modelling the impacts of climate extremes in a changing climate: a preliminary case study of household water harvesting in Southeast Queensland. Proceedings of the 18th World IMACS / MODSIM Congress, Cairns, Australia, 2009.

[30] RainwaterTanksDirect, Huge savings on larger rainwater tanks. RainwaterTanksDirect, 2011.

[31] Marsden Jacob Associates, The cost-effectiveness of rainwater tanks in urban Australia. National Water Commission, Commonwealth of Australia, Canberra, 2007.

[32] Sharma, R. H. \& Shakya, N. M., Hydrological changes and its impact on water resources of Bagmati watershed, Nepal. Journal of Hydrology, 327, 3-4 2006), 315-322.

[33] MOPE, Initial National Communication to the Conference of Parties of the United Nations Framework Convention on Climate Change. City, 2004.

[34] Pitre, C., Will the well go dry: Potential impact of climate change on groundwater systems used by municipal water suppliers. Proceedings of the 2005 Climate Change Conference, King County, Seattle, WA, USA, 2005.

[35] Howard, G. \& Bartram, J., Domestic Water Quantity, Service Level and Health, World Health Organization, Geneva, 2003, $<$ www.who.int/water_sanitation_health/diseases/WSH03.02.pdf $>$.

[36] DFID, key sheet series on the impact of climate change on poverty focussing on vulnerability, health and pro poor growth, Department for International development (DFID) UK, City, 2004.

[37] Hijioka, Y., Takahashi, K., Y, M. \& H., H, Impact of global warming on waterborne diseases. J. Jpn. Soc.Water Environ., 25, pp. 647-652, 2002. 
574 The Sustainable City VII, Vol. 1

[38] AWWA, Optimizing Filtration Operations. American Water Works Association, 2006.

[39] Regmi, B. \& Adhikari, A., Human Development Report 2007/2008: Fighting climate change: Human solidarity in a divided world. Human Development Report Office, 2007.

[40] ADB, Technical assistance completion report, Enabling the Private Sector to Undertake Poverty- Focused Water Distribution and Strengthening of Institutional Reforms in Kathmandu Valley. Asian Development Bank, Kathmandu, 2008. 